\section{Aporte de la etnomusicología al debate sobre música y cultura popular: Algunos apuntes}

\section{Contribution of ethnomusicology to the debate on music and popular culture}

\author{
Enrique Cámara de Landa \\ Universidad de Valladolid \\ camaralafyl.uva.es \\ https://orcid.org/0000-0001-5796-9056
}

\section{Resumen}

Enrique Cámara es Doctor en Etnomusicología, Catedrático en la Universidad de Valladolid (España) y actual presidente de la Sociedad Ibérica de Etnomusicología. Posee amplia experiencia en el estudio de las músicas tradicionales hispanoamericas, italianas e hindúes. Su trabajo aborda procesos de hibridación musical, improvisación, revival, preservación y conservación de músicas consideradas folclóricas, así como aspectos de migración, metodología, transcripción y análisis, polifonía y etnomusicología audiovisual.

En este número presentamos la Conferencia realizada por este académico en la Conferencia Internacional sobre Comunicación y Cultura Popular en América Latina y el Caribe, realizada los días 3, 4 y 5 de septiembre de 2019 en la casa central de la Universidad de Chile y organizada por los responsables de este dossier. La tesis principal del texto es que en la literatura etnomusicológica escasean los textos que sometan a debate la relación entre la música y la cultura popular Isi bien existen notables excepciones). La contribución de la disciplina en este ámbito reside en el enriquecimiento del debate (recibido desde otras áreas) más que en la generación de una teoría general.

\section{Introducción}

Este artículo es resultado de mi participación en la Conferencia Internacional sobre Comunicación y Cultural Popular en América Latina y el Caribe "Representaciones y proyectos políticos hoy" que tuvo lugar en Santiago de Chile en Septiembre 20191. He modificado los contenidos para ajustarme con mayor pertinencia a lo que se espera de un trabajo escrito, si bien he mantenido el título original. Este fue propuesto por Christian Spencer, lo que me indujo a intentar presentar de forma crítica y sintética parte de la producción bibliográfica relativa al tema². La búsqueda de textos relevantes condujo a una constatación poco estimulante y tal vez errónea len cuyo caso arrojaría cierta esperanza de éxito en futuras pesquisas): no parece existir una tradición etnomusicológica consistente y consolidada de debate sobre las relaciones entre música y cultura popular. Los estudiosos de la disciplina acuden a otras lalgunas próximas, como la antropología, la filología o la semiótical para equiparse con herramientas y categorías epistemológicas aplicables a sus investigaciones, como lo hacen con áreas de interés (los estudios culturales, por ejemplo), estrategias (deconstrucción, entre otras), técnicas (tomadas principalmente de la musicología histórica y sistemática relativas al análisis musical) o teorías críticas (decolonialismo es una de ellas). Abunda, en cambio, el abordaje etnomusicológico de las músicas consideradas populares o vinculadas con la cultura popular, si bien algunos autores que focalizan ambos conceptos manifiestan alguna dificultad para articularlos ${ }^{3}$.

En los siguientes párrafos señalo aspectos de la problemática terminológica que afecta al sector y destaco contribuciones de los etnomusicólogos que mantienen vinculación explícita con la cultura popular. Con ello espero contribuir a delinear un panorama inicial sobre la producción de la disciplina en torno a un tema actual necesitado de estudios preliminares que faciliten futuras inves- 
tigaciones. Puesto que se trata de un estado de la cuestión destinado a estimular la consulta bibliográfica, he intentado silenciar mi voz crítica y presentar, de manera lo más escueta posible, las categorías tratadas en los textos.

\section{Ambigüedades terminológicas}

Surgen cuando se pretende nombrar categorías con carácter científico. En el presente caso tenemos, por un lado, la palabra popular (del latín popularis, relativo al pueblo) que históricamente nos remite al volk en cuanto pueblo definido con carácter general, sin distinciones de clase o lugar de residencia; o bien hace referencia a clases sociales desprovistas de educación superior, con escasa disponibilidad de medios económicos, menor capital cultural o acceso restringido a cargos de poder labundan en la etnomusicología reciente los usos que aluden a los vínculos entre música y clase social, como veremos). El término popular ha sido a menudo asociado a "la gente" en oposición a las clases dominantes y la oficialidad. Así viene siendo utilizado por el discurso nacionalista africano, explica Erlmann (1991), quien caracteriza a la música popular negra sudafricana como creación reciente en las ciudades en desarrollo a partir de fuentes tradicionales len esto recuerda a las proyecciones sudamericanas, las músicas de raíz españolas y el folk revival en otras áreas), relacionada además con un amplio espectro de clases sociales (incluso como puente entre sus diferencias) y con evidencia del uso de elementos de la sociedad blanca hegemónica (a la cual no deja de oponerse) para beneficio de las clases trabajadoras y también de los migrantes internos. Éstos - explica el autordurante los eventos de danzas competitivas "afirman lazos de solidaridad basados en el origen regional y étnico común" (p.101), experimentan orgullo por el patrimonio heredado y transforman los conflictos intergrupales del pasado en combates representados de manera estilizada (tal vez de un modo no muy distinto de lo que sucedió con la capoeira en Brasil y los tinkus en países andinos). Estas transformaciones - prosigue Erlmann - no eliminan la peligrosidad que representa la clase trabajadora urbana para la hegemónica, que intenta ajustar las prácticas culturales emergentes de aquella a su propia noción de cultura popular (p.105). En este texto encontramos una de las escasas apariciones del término deba- te en relación con tales procesos de domesticación de prácticas populares, que se producen en sentido vertical - desde arriba hacia abajo - u horizontal Icomo parte de la adaptación a nuevos ambientes sociales). La aplicación de tal visión dinámica conduce al estudioso a declarar la inutilidad del concepto de culturas de clases homogéneas en el caso sudafricano (consideración ésta recurrente en relación con distintos países). Richard Middleton (2003) va más allá al denunciar el carácter "sucio" del concepto de "people/popular" en cuanto corrupto desde el comienzo al proceder de un espacio discursivo de origen incierto, contenido cambiante y abierto al debate (lo cual, visto el enfoque del presente texto, no lo invalida a priori, sino que invita a discutirlo).

El vocablo música también debe relativizarse a quienes lo utilizan'. En el caso que nos ocupa (su asociación con "popular") suele oponerse al de "clásica", también de relevancia emic y, por lo tanto, preferible a otros: erudita, académica, escrita, de arte, docta... en lo relativo a tipos de música ningún término convence, lo que obliga a apelar a convenciones o a especificar el campo semántico elegido en cada caso.

Desde que William John Thoms la propusiera en 1848, la palabra folklore fue objeto de aceptaciones, rechazos y sustituciones por otras, como "tradicional" lusado en Francia para nombrar un tipo de expresión musical no contaminado por los mecanismos del folk revival). Hoy también en España, por ejemplo, nos entendemos cuando hablamos de música tradicional, con tal de que remitamos a un contexto geográfico local, puesto que en los países de Oriente se utiliza este término para denotar el equivalente de lo que Occidente denomina clásica, es decir, las músicas pertenecientes a las grandes tradiciones pluriseculares que cuentan con teoría, especulación y prestigio social llas tradiciones indostánica y carnática de la India constituyen un ejemplo) $)^{5}$. También en Italia el fenómeno del revival condujo a los etnomusicólogos de ese país a bautizar como popolare a la música equivalente a la que latinoamericanos seguimos denominando en esos momentos "folklórica" Icon las superposiciones semánticas que denunciaron Carlos Vega y otros estudiosos) y llamar popolaresca a sus manipulaciones en contextos "no tradicionales". Tal elección terminológica obligó a los italianos posteriormente a utilizar el término inglés popular para nombrar a la música que en áreas hispanohablantes se califica 
como popular urbana, a partir de varias sugerencias paralelas y apelando a una dicotomía rural-urbano hoy en crisis ${ }^{6}$. Sería posible proseguir con estas disquisiciones mencionando las expresiones mesomúsica, acuñada por Carlos Vega en la década de 1960 (Vega, [1966] 1979), folklore urbano (que remite a uno de los extremos del continuum establecido por Robert Redfield), o folk music lasociada a procesos de folklorismo surgidos de la conciencia de propiedad del patrimonio cultural), pero creo que bastan las que acabo de mencionar para reconocer que la historia y la teoría de la disciplina considerada aquí - la etnomusicología - parecen estar condenadas a la ambigüedad semántico-terminológica y que los investigadores apelan a convenciones más o menos compartidas para nombrar los tipos de música que estudian, cosa que también sucede con los contenidos y alcances de este campo del saber? ${ }^{7}$.

\section{Música y cultura popular}

El interés por considerar a la música en relación con la cultura popular se manifiesta ya entre estudiosos influidos por el evolucionismo y el difusionismo decimonónicos. Marius Schneider, por ejemplo, lo declara en 1954, pero crece exponencialmente con las corrientes que influyeron posteriormente en la etnomusicología (particularismo, funcionalismo, estructuralismo primero, antropología de la música, simbolismo, estudios culturales y coloniales, entre otras, después) e inunda la producción bibliográfica del campo de estudios sobre música popular, cuyo crecimiento exponencial lo ha convertido en disciplina autónoma y obliga a evitar su mención detallada aquí.

Si nos ceñimos - con los inevitables solapamientos de una empresa utópica - al ámbito de lo que seguimos considerando etnomusicología lnos guste o no el prefijo "etno"), podremos armar diferentes taxonomías temáticas sin necesidad de abandonar las relaciones entre música y cultura popular, por lo que la siguiente, que considero pertinente en este caso, dista de ser la única o la mejor y presenta sólo algunos ejemplos de textos para cada tema.

\subsection{Asimetrías sociales, económicas y políticas}

Muchos estudiosos las tienen presentes o las abordan desde distintos ángulos. Es el caso de Thomas Turino (1984) cuando escudriña lo que denomina "factor hegemónico" y "factor de la identidad" en la búsqueda de movilidad social por parte de músicos subalternos en Perú y el uso de símbolos culturales del propio grupo o la adopción de los dominantes. Desde una posición que elimina barreras entre disciplinas musicológicas, Alejandro Madrid (2010) trata la vinculación entre poder y nacionalismo musical al considerar, por ejemplo, la doble condición de marginalidad y emblematización a la que son sometidas las expresiones musicales autóctonas por parte de las corrientes asociadas al nativismo y el indianismo en los discursos sobre la identidad nacional en contextos de homogeneización y control durante la constitución de estados nacionales. Irma Ruiz (2018) - centrada en los conceptos, objetos y prácticas musicales- explicita estrategias de ocultamiento por parte de los guaraníes ante el dominador blanco. Otros autores las tratan en relación con los criptojudíos perseguidos por la Inquisición (Cohen, 2011); los afroamericanos aparentemente sumisos ante la religión dominante -Neal (1999) utiliza la expresión "transcripción oculta"9-; mientras otros casos hacen referencia al silenciamiento de las clases bajas por parte del discurso oficial en el caso mexicano (Simonett, 2001); a la música escondida, prohibida, promovida o permitida, Susana Sardo (2010) aterriza estas categorías en Goa; a la ignorada, las culturas rom en Europa incluso desde la etnomusicología, que no tuvo en cuenta la dimensión histórica de estos pueblos, según Luc Charles-Dominique (2011); la que es central en la cultura perseguida, González Hernández (2016) sobre la flauta pochó y el tunkul yokot'an en Tabasco; o la heterodoxa, rechazada pero vigente en la cultura popular (como sucede hoy con las cofradías sufíes en Marruecos) ${ }^{10}$.

Otros tipos de agencia son observados por autores más próximos a la Escuela de Birmingham que a la de Frankfurt. Un ejemplo: Keith Negus ([1999] 2005) señala la presión ejercida por activistas sobre grandes sellos discográficos para que se remunere a los artistas negros con equidad, así como las redefiniciones de estilo con que los músicos de rap consiguen atravesar barreras sociales y culturales pese a la acción inicial excluyente de las multinacio- 
nales (p.182)"1; la agencia de la "comunidad musical" (p.214), discursos de autenticidad en la música country asociados con gente corriente, comunidad y familia (siempre en relación con la industria, pp.224225) y, en muchos puntos de su monografía, la relación de géneros musicales con espacios y agentes sociales (p.237). La inversión de significados también pertenece al ámbito de la agencia subalterna, otro tema del que encontraremos varios ejemplos en distintos continentes y regiones ${ }^{12}$, Latinoamérica incluida ${ }^{13}$.

La acción de auto-ocultamiento constituye una cara de la moneda; la otra es la invisibilización y marginación de grupos sociales subalternos por parte de los hegemónicos, de abordaje recurrente en la literatura del sector. Véanse, entre otros ejemplos, los trabajos de Walter Sánchez y Pablo Cirio sobre afrobolivianos y afroargentinos, respectivamente; con numerosas referencias a estrategias desde los sectores involucrados en los conflictos de raza y clase. También la "estética de la opacidad" en las expresiones vocales de los afrobrasileños analizados por José Jorge de Carvalho en un texto que considera la relación entre géneros musicales o de danza - a partir de sus nombres-y el "inconformismo y conflicto dentro de un campo de desigualdad social y de ideologías contrastantes" $(2010$, p.127), así como los estereotipos construidos sobre ellos desde observadores externos: "En la medida en que están tocando música, se supone que todo está bien; el subtexto es que tocar música suspende, o por lo menos suaviza, la agonía de la condición de esclavo" (2010, p.129). También Finnegan (1989) estudia a los músicos "invisibles".

En un trabajo sobre "las ontologías y epistemologías de lo acústico, particularmente la voz (...) de manera ambigua ubicada entre 'naturaleza' y 'cultura'"'(p. 3) durante el período colonial y el siglo XIX en Colombia, Ana María Ochoa-Gautier (2014) enfoca la "auralidad", es decir, considera las técnicas audibles cultivadas tanto por las elites letradas como por las personas históricamente consideradas "iletradas", lo cual la obliga a consultar una gran variedad de fuentes para dar cuenta de prácticas protagonizadas por clases populares generalmente ignoradas o malinterpretadas por la literatura del sector y revisar asimetrías sociales implícitas en la construcción de la modernidad. Constructos ideológicos relativos a la denominada
- por distintos autores- "cultura popular" son señalados en varios capítulos del volumen, como lo son en tantos otros textos que no es posible mencionar aquí sin caer en la dispersión disciplinar. Véanse las referencias a los repertorios y prácticas musicales "patrimonio" de la cultura/s popular/ es en relación con aspectos de identidades nacionales y subcontinentales, creatividad, solidaridad, ideología, folklore, iniciativas gubernamentales, modelos internacionales e incluso rechazo de los movimientos contrahegemónicos en el trabajo sobre Nueva Canción Chilena de Patrice McSherry (2015), quien se aproxima a la etnomusicología desde las ciencias políticas lun ejemplo entre muchos de la porosidad de fronteras interdisciplinarias que hace difícil establecer límites bibliográficos en el presente estado de la cuestión).

A los trabajos sobre relaciones entre música y política que comenté (Cámara ([2003] 2016) cabría agregar muchos más, ya que se trata de un área temática en fuerte desarrollo (Rice, 2014). Si bien predomina la focalización en los procesos protagonizados por -o que afectan a- miembros de la denominada clase popular o working class, a menudo se enfocan los que involucran a distintos segmentos de la sociedad, de los que se estudian diversos tipos de interacciones. La actual relevancia del tema, que dialoga con corrientes también en crecimiento como la etnomusicología colaborativa, no debe hacernos olvidar que de alguna manera el interés por las clases subalternas, las comunidades rurales, los indígenas Itérmino que, si bien ha sido desplazado por otros en áreas como Latinoamérica, sigue vigente, por ejemplo, en Australia justamente entre componentes del movimiento que estoy señalando) ${ }^{14}$, siempre ha existido en la disciplina y que en el último medio siglo la atención a "los sin voz"15 ha estado acompañada por análisis de fenómenos interclasistas. En Brasil (país en el que se produce abundante literatura sobre el área), Mário de Andrade (1963) fue uno de los primeros estudiosos en interesarse por los cantos colectivos durante las manifestaciones callejeras de carácter político ${ }^{16}$. Treinta años después, Gage Averill (1997) combinó el análisis de iniciativas de distintos sectores sociales al tratar simultáneamente la revolución y el populismo desde diversas instancias lincluida la acción de clamar por un líder carismático aunque fuera dictadorl en las canciones vudú "adversarias" en Haití. 
Los trabajos sobre asimetrías de poder entre clases hegemónicas/dominantes y subalternas/dominadas mencionados aquí especifican aspectos de la relación entre prácticas musicales y cultura popular. Tricia Rose (1994) aborda la cultura de masas y el uso de lengua, danza y música por parte de los oprimidos - término literal, usado junto a poor folks - "para burlarse de los que están en el poder, expresar rabia y producir fantasías de subversión" (p.99) como forma de resistencia. La autora se refiere a los raperos, quienes "en la cultura popular contemporánea han sido perros callejeros ruidosos y rebeldes" (p.102) y hoy establecen diálogos con varones y mujeres de la clase trabajadora y rechazan las jerarquías estéticas codificadas racialmente en la cultura popular estadounidense, pero también señalan la contradicción entre la carga contrahegemónica con que dotan a algunas letras de sus canciones y el soporte a determinadas desigualdades de poder social que se advierte en otras. Contradicciones intraculturales que se suman en ocasiones a la tantas veces mencionada colonización interna, como la "sanscritización" impuesta que denuncia John Napier (2011) o la pretensión de exclusividad sobre géneros y prácticas musicales por parte de las castas altas en Goa, por ejemplo, donde la élite no reconoce la movilidad social en su uso o lamenta su adopción por parte de castas inferiores resultante de la difusión operada por los mass media. Sardo (2010) analiza el rol de la música como marcador social y los fenómenos clasistas que se verifican aún hoy en India.

“Mi análisis de la tecnobanda como fenómeno de la música y la danza, en particular, muestra la importancia de una audiencia activa y participante en la configuración de la cultura popular", afirma Simonett (2001, p.15), quien en distintos apartados de su monografía se refiere a la imprevisibilidad de la cultura popular ljunto a la fuerte connotación de clase baja y atraso del término "popular"), así como a la relevancia que asume la música popular para la situación social de sus usuarios, las condenas de las élites hacia determinados géneros y su estigmatización a través de clichés y rótulos, la ausencia de documentos sobre la percepción de las clases populares ante estos ataques, las negociaciones interclasistas durante eventos como el carnaval lo la superación de barreras de clase como estrategia de autopromoción), los conflictos ante la posibilidad de emblematización de un género popular limposible no evocar la historia del tango rioplatense y de tantos otros géneros) y el surgimiento de estereotipos degradantes que son expresión de lo censurado lotro ítem sumamente difundido y tratado en tantas áreas).

\subsection{Procesos y funciones}

Apropiación, pertenencia, resemantización, electoralismo, exotización, movilidad social, identificación, empoderamiento, interacción, toma de conciencia o representación, agencia contracultural, interpelación, nostalgia-evocación-memoria, evasión, son algunas de las cuestiones (generalmente consideradas desde la óptica procesual) cada vez más presentes en los textos etnomusicológicos que desarrollan temas de cultura popular. Como lo son las funciones, explícitamente señaladas o que es posible deducir de la lectura, que abarcan amplios espectros, desde la denuncia-contestación-protesta-manifestación hasta la proclama revolucionaria, o desde las necesidades experimentadas por las clases populares hasta las dinámicas de aceptación-rechazo, estímulo del fervor, catarsis, crítica intragrupal e interclasista, obsecuencia, rivalidad, controversia, burla, construcción de prestigio lo su incrementol, confirmación de roles de género lincluso a través de su inversión ritual o institucionalizada), emblematización, aceptación de asimetrías, entre otras. Un listado que es posible ampliar ad infinitum sin agotarlo, ya que un solo estudio monográfico puede contener muchos ítems, como sucede con los fenómenos de exuberancia, obscenidad, exageración, juego verbal, parodia, consumo desenfrenado, burla, humillación, sexualidad, licencia, transgresión, enmascaramiento, conflicto y representación de jerarquías mencionados dentro de un solo paréntesis de texto en relación con la actividad vinculada a la música de haitianos de clase baja durante el carnaval. Averill (1997) desarrolla una monografía sobre la historia musical de los procesos protagonizados por clases sociales, con abundante presencia de la cultura popular ${ }^{17}$.

Su afirmación sobre "el desdén de una clase de haitianos que rechazan el folklore debido a 
sus orígenes de clase baja" (p.63) aparece con variantes en la literatura etnomusicológica latinoamericana (basta con cambiar la palabra "folklore" por "tango", "cumbia" o tantas otras). Si el término procesos remite en nuestro imaginario principalmente al espacio de las prácticas compartidas, conviene recordar que también puede aplicarse a los que se verifican en los individuos, así como en los objetos, rasgos y estructuras "específicamente" musicales linstrumentos, sistemas sonoros, géneros y formas), lo que no obsta para que se los relacione con su uso por parte de las clases sociales. Esto no siempre sucede, como sabe quien haya leído trabajos de la primera mitad del siglo pasado en castellano, pero también en los publicados en otros idiomas: en Origins of the Popular Style, Peter Van der Merwe (1989) concede prioridad a la descripción de estructuras musicales al ocuparse tanto de música clásica como popular (dicotomía que asume, puesto que aplica estos dos términos] desde una perspectiva pancrónica y universalista, si bien excluye los espacios indígenas ${ }^{18}$. En este sentido está casi en las antípodas de lo que encontramos mayoritariamente en los artículos de revistas como Ethnomusicology (por citar sólo unal, en los que los rasgos específicos del lenguaje musical sólo son mencionados cuando dan sentido a los textos, casi siempre centrados en temas como poder, violencia lacoso sexual incluidol, posthumanismo - agencia de objetos y factores no humanos-, valor adjudicado a bienes materiales e inmateriales y su circulación Igustos e ideales estéticos, pero también dinero, ideologías, etcétera.), ecocentrismo (destrucción versus preservación-sostenibilidad de los ecosistemas) y muchos otros. Todo ello sin abandonar la actitud reflexiva, presente especialmente en áreas como la ya mencionada de la etnomusicología colaborativa, pero también creciente en espacios como el latinoamericano; el ejemplo más reciente que he encontrado es el de Leonardo Waisman, musicólogo de amplio espectro que confiesa: "Pensar desde la subalternidad es, para muchos de nosotros, un proyecto difícil ya que, en última instancia, nosotros fuimos los colonizadores. Más que subalternos nativos, somos dominantes transportados al territorio de la subalternidad" (2020, p.594).

\subsection{Otros temas}

Intentaré ser breve en la enumeración temática que sigue, necesariamente incompleta y con algún ejemplo para cada caso:

Diásporas de todo tipo son relacionadas con música de clases subalternas:

Sobre los africanos esclavizados, Victoria Eli (2010) destaca su "papel fundamental en el proceso integrador de la cultura del Caribe" pese a los "mecanismos de deculturación" aplicados por el poder colonial para impedir su cohesión social (pp.173-175). Espectacularización:

Chang (2011) menciona la voluntad de deslocalización en el sentido de "exclusión de las prácticas locales, a la vez que se construye un paisaje cultural tranquilizador" (p.53), en referencia a un modo de ignorar las culturas locales, aunque se extraigan y usen sus músicas en el escenario. Otros se preguntan cómo pueden las "músicas turísticas satisfacer al mismo tiempo las expectativas de las comunidades locales que se supone que representan y las de los turistas" (Desroches 2011, p.62), acerca de músicas de procedencia afro ayer prohibidas y hoy espectacularizadas en Martinica. La domesticación de la danza ingoma en Sudáfrica pasó, explica Erlmann (1991), "de una forma de cultura popular militante, opositora y reprimida a una atracción turística [lo que constituye un ejemplo del] carácter procesual y dinámico de la cultura popular en África" (p.96-97).

\section{Identificación-exclusión:}

Martin Stokes (2003) detecta un contraste entre la antipatía de intelectuales europeos hacia la cultura popular estadounidense y la identificación de migrantes y marginales residentes en espacios urbanos de aquel continente con la experiencia de afroamericanos expresada en el rap y el hip-hop (si bien otros autores recuerdan que la asociación del género con ámbitos sociales marginales en Estados Unidos no siempre se verifica en otros continentes). Racismo y clasismo sistemáticos afectan a músicos africanos del hip-hop emigrados a Gran Bretaña, explica Mark (2011), mientras que las indicaciones de Simonett (2001) acerca de la identificación que exhiben miembros de bandas de clases populares con sus localidades de procedencia me recuerdan a las 
que manifiestan con orgullo los grupos de jóvenes de barrios marginales entonando vidalas en el centro de la ciudad argentina de Salta durante el carnaval.

\section{Tipos de música y sistemas de valores:}

Lucy Green (2003) especifica cómo el concepto de ideología beneficia a los grupos sociales de alto nivel económico y el uso de las categorías musicales - clásico, popular - por parte de sus miembros en pro de sus sistemas de valores, que también condicionan la educación al destinarla a reproducir la diferenciación social en materia de clase, género y etnicidad. Michael Denning (2015) denuncia los clichés valorativos adjudicados a categorías de trabajadores desacreditadas y a gente de estratos sociales inferiores, la influencia formativa sobre músicos jóvenes de prácticas musicales subalternas, los puertos como puntos de encuentro entre distintas clases de músicos ly la riqueza subyacente al caos en ese soundscapel ${ }^{19}$, el desempeño de músicos de clases populares en espacios como dance halls, cabarets o burdeles, los efectos de la accesibilidad de los reproductores de sonido entre los estratos de bajos recursos económicos y el uso de las voces de sus habitantes por parte de la industria discográfica o las luchas entre movimientos sociales y políticos en los procesos de nacionalización de músicas vernáculas.

\section{Música y sociedad:}

La postura interpretativa que busca relaciones entre los ámbitos musical y social pervive en trabajos como el de Rafael Menezes (1999), quien aplica metodologías analíticas a una canción brasileña perteneciente al género samba para explicar las vías a través de las cuales este género expresa conceptos fundamentales de la realidad sociocultural del país. La pertenencia social puede ser suspendida durante un evento musical que involucra a contendientes de diversa extracción, explica Elizabeth Travassos (2000) en relación con los duelos cantados del nordeste de Brasil y su uso para negociar tensiones de jerarquía y diferencia. Otro aspecto inter-clases lla contribución material y simbólica de cada sector de la población durante un festivall es puesto en relación con la distribución de recursos en la comunidad por Suzel Ana Reily (1994), mientras Erlmann, en su ya citada monografía de 1991, estudia el modo en que las clases sociales en Sudáfrica imaginan culturas musicales coherentes de base étnica les decir: aplicando el criterio de etnicidad en la delimitación de clases), a la vez que relativiza las dicotomías más recurrentes en la producción etnomusicológica (rural y urbano, tradición y modernidad, negro y blanco o hegemonía y resistencial, crítica que también desarrolla Giuriati (2017a, 2017b) en relación con prácticas musicales que desafían taxonomías en el área de Nápoles ${ }^{20}$.

\section{Conclusión: alguien debate}

Entre los escasos textos dedicados específicamente al debate sobre música y cultura popular figura el de Ross Cole, quien, tras recordar que el concepto de cultura popular debe ser historificado, estudia el período 1880-1920 en Gran Bretaña para identificar distintos usos del término "popular", critica concepciones de estudiosos acerca de la cultura popular lo sobre las distinciones entre lo "realmente popular" -el 'incontaminado' folklore- y las canciones de autor), comenta los escritos sobre lo impredecible del éxito de determinadas canciones que entraban en la categoría de "populares" por ser de consumo masivo y atiende a la dificultad de definir lo popular en música. Tras establecer diez significados distintos en el uso de la expresión popular music durante la modernidad, propone rearmar la "cartografía de lo popular" reactivando discusiones - entre musicólogos o transdisciplinarias- sensibles a los fluctuantes hábitos musicales de "la gente" y observando los actos individuales de compromiso con la música lalta o baja, contracultural o convencionall.

Encuentro esta llamada al diálogo oportuna para recordar una frase de Willard Rhodes (1957) citada por Anthony Seeger en una conferencia durante su visita a la Universidad de Valladolid en 2018: "Para el músico, gran parte de esta música [popular] es común, aburrida y carente de valores estéticos y artísticos. Para el etnomusicólogo es interesante y significativa porque tiene valor para quien la produce y consume" $(\text { p. } 4)^{21}$. De manera a menudo implícita, las relaciones entre música y cultura popular son una constante en la literatura etnomusicológica, si bien el debate escasea (tal vez por una tácita delegación en otras áreas del 
saber). Al parecer, la contribución más consistente de la disciplina reside, más que en la generación de teoría general, en el enriquecimiento de la recibida desde otras áreas del saber gracias a su aplicación a realidades sumamente significativas para las personas y los grupos sociales ${ }^{22}$.

\section{Notas}

1. Agradezco a los organizadores del evento, en particular a Chiara Rossana Sáez Baeza y a Christian Spencer Espinosa, su amable invitación.

2. Por falta de espacio, no ampliaré el marco teórico fuera de esta referencia ni la especificación metodológica. Véase Béhague (1993) y Romero (1986) -entre otros- sobre musicología en Latinoamérica.

3. Aludo a prácticas, comportamientos, ideas y valoraciones en el ámbito de la producción, difusión y recepción de lo que muchas sociedades denominan música.

4. Debates sobre los conceptos de música y musicalidad humana figuran en Blacking ([1973]2006) y Giannatasio (1992).

5. Giannattasio (2017) expone otras críticas a la expresión 'música tradicional'

6. Traté la poligénesis de esta expresión en Cámara de Landa (2016), así como un amplio abanico de contenidos semánticos de la expresión "cultura tradicional" en Cámara de Landa 2016.

7. Sobre definiciones de musicología comparada y etnomusicología, ver Kunst (1955) y Merriam ([2001]1977). Textos más recientes abordan el tema sin aportar grandes novedades.

8. Ver, entre otras guías bibliográficas sobre música popular, Cámara de Landa e Iglesias (2016). Indispensable es la excelente introducción al área de Middleton (1990), así como la de Manuel (1988) para países "no occidentales" (he abordado los contenidos de ambos, incluidas las menciones explícitas a la cultura popular, en Cámara de Landa [2003]2016). También recomiendo consultar González (2013) sobre Latinoamérica y Hamm (1995) sobre narrativas, así como Tagg (1979) y Moore (2003) acerca del análisis musical y los textos con perspectiva semiótica de Gino Stefani. El volumen de Cámara de Landa \& Díaz (2019), consultable online, contiene un listado selectivo de sociedades y revistas científicas del sector (con sus relativos hipervínculos a contenidos).
9. El subtítulo del libro de Neal - Black Popular Music and Black Popular Culture- encaja de tal modo en el tema abordado aquí, que merece la invitación a leerlo.

10. Ver Cámara de Landa (en prensa). Ver Stokes (1992) sobre estrategias de instrumentistas profesionales urbanos para contrarrestar las condenas del arabesk - un género popular turco- por parte de la tradición kemalista dominante y las interacciones de poder entre estratos sociales vinculados al poder y la religión.

11. Sobre la cualidad transfronteriza lentre clase, estatus, edad o sexol de la condición de músico, ver Hernández-López (2016).

12. Ver Dawe (1998) sobre los procesos de negociación y adaptación a la lógica del mercado por parte de los músicos cretenses y las estrategias que desarrollan en relación con los recursos, los competidores y los clientes lel autor evidencia la creatividad con que responden a presiones y potenciales conflictos que reciben en su cualidad de mediadores entre distintos ámbitos).

13. Ver Arrivillaga-Cortés (2016) sobre la resemantización del Baile de la Conquista, de pedagogía de la dominación a expresión de resistencia en la versión elaborada por los k'iche'.

14. Todos los capítulos del volumen colectivo editado por Katelyn Barney (2014), algunos de los cuales fueron escritos en colaboración entre insiders y outsiders, lo utilizan, lo que indica consenso previo para nombrar al Otro o a sí mismo.

15. Título de varios programas de promoción sociocultural en países castellanohablantes. Sardo (2010) utiliza la expresión "la voz del subalterno".

16. Convendrá matizar los comentarios sobre la ambivalencia en la aproximación de Andrade a la cultura popular mencionada por Viveiros (2004). Véanse, entre tantos otros trabajos posteriores al del brasileño, el texto de Jaume Ayats (1997) sobre la expresión sonora durante manifestaciones públicas y el de Norijo Manabe (2013) sobre la música en las demostraciones antinucleares en Japón.

17. He propuesto otro listado de funciones detectables en las prácticas musicales del carnaval en otra región de Latinoamérica (Cámara, 2006), sin olvidar los de contenido estético, las diferencias de clase en determinadas prácticas musicales o la omnipresente temática de la experiencia amorosa en todas sus vertientes (incluido el odio, claro).

18. No faltan hoy autores que relativizan esta dicotomía en relación con las clases sociales (cuyas diferencias también son matizadas en determinados estu- 
dios sobre dinámicas actuales). En la ponencia que dio origen al presente texto utilicé dos versiones de una melodía lla "marcha nupcial" en el tercer acto de Lohengrin de Richard Wagner y citada en la canción pop "Vestida de novia" de Ramón Bautista "Palito" Ortegal para navegar por ambigüedades terminológicas, corrientes de la etnomusicología y clichés adjudicados a la relación entre repertorios musicales y clases sociales.

19. Los orígenes de los géneros musicales populares a menudo suelen ser identificados entre clases trabajadoras de los arrabales len Argentina, Francia, Co- rea, Canadá, etc.) y analizados con distintos enfoques.

20. He dedicado dos textos a la creatividad de los músicos 'tradicionales' que rompen distintos tipos de fronteras (Cámara, 2017; 2018).

21. Ver Julia Escribano (2018) sobre esta conferencia.

22. Quedan para una futura ampliación del tema las interesantes referencias y consideraciones sobre dinámicas de la cultura popular en textos etnomusicológicos que las tienen especialmente en cuenta, como Manuel (1998), Negus (2005), Blacking (1995), Wade 2000), Taylor (2001) y Valenzuela (2003).

\section{Referencias}

Andrade, M. (1963). Música, doce música. São Paulo: Livraria Martins Editora.

Arrivillaga-Cortés, A. (2016) “El Baile de la Conquista: resignificación liberadora”. En: Los sonidos de nuestros pueblos. Escuchas desde el Sur (pp. 57-70). Tuxtla Gutiérrez: UNICACH.

Averill, G. (1997). A Day for the Hunter. A Day for the Prey. Popular Music and Power in Haití. Chicago \& London: The University of Chicago Press.

Ayats, J. (1997). Dos situaciones de expresión sonora colectiva: Las manifestaciones en la calle y en los estadios deportivos. Trans Iberia. http://www.sibetrans.com/trans/

Barney, K. (ed.) (2014). Collaborative Ethnomusicology. New Approaches to Music Research between Indigenous and Non-Indigenous Australians. Melbourne: Lyrebird Press.

Béhague, G. (1993). "Latin America." En Ethnomusicology, editado por Helen Myers. Vol. 2, Historical and Regional Studies (pp. 472-494). London: Macmillan.

Blacking, J. A. R. (1995). Music, Culture, \& Experience. Selected Papers of John Blacking. Chicago \& London: The University of Chicago Press.

Blacking, J. A. R. ([1973] 2006. ¿Hay música en el hombre? Edición española al cuidado de Francisco Cruces. Madrid, Alianza Editorial.

Cámara de Landa, E. ([2003] 2016a). Etnomusicología. Madrid: ICCMU.

Cámara, E. (2006). Entre Humahuaca y La Quiaca. Mestizaje e identidad en la música de un carnaval andino. Valladolid: Universidad de Valladolid.

Cámara, E. (2016b). “Tradición, patrimonio y música popular en Castilla y León: el caso de Soria”. En El patrimonio cultural inmaterial de Castilla y León: propuestas para un atlas etnográfico. Luis Díaz Viana González (ed.) (pp 249-270). Madrid: Editorial CSIC.

Cámara, E. (2017). "Polyphonic arrangements for a monodic tradition: rituals and musical creativity today in Soria". En European Voices III. The Instrumentation and Instrumentalization of Sound.Local Multipart Music Cultures and Politics in Europe. Ardian Ahmedaja (ed.) (pp. 87-99). Vienna: Boehlau.

Cámara, E. (2018). “Estrategias creativas actuales en músicos sorianos”. En Música y construcción de identidades: poéticas, diálogos y utopías en Latinoamérica y España. Victoria Eli Rodríguez y Elena Torres Clemente (eds.) (pp. 319-334). Madrid: Sociedad Española de Musicología. 
Cámara de Landa, E.(en prensa). "Ritual, salud y convivencia interreligiosa: expresiones sonoras y cinéticas de los miembros de las fraternidades marroquíes". En D. Vicente Blanco, S. Asensio Llamas, I. Fernández de la Mata y P. Tomé Martín (eds.), "Salvajes" de acá y de allá: memoria y relato de nosotros. En torno a los trabajos de Luis Díaz Viana. Madrid: CSIC.

Cámara de Landa, E. \& Díaz, L. (2019) Para conocerte mejor. Recursos institucionales y bibliográficos para la investigación en música tradicional y popular. SIbE / Universidad de Valladolid.

https://www.sibetrans.com/manuales/public/docs/manual-para-conocerte-mjor.pdf

Cámara de Landa, E \& Iglesias, I. (2016). “Apéndice 2. Bibliografía selectiva sobre música popular urbana”. En Etnomusicología (pp. 477-488). Madrid: ICCMU.

Carvalho, J. J. de. (2010). “Un panorama de la música afrobrasileña”. En A tres bandas. Mestizaje, sincretismo e hibridación en el espacio sonoro iberoamericano (pp. 125-135). Tres Cantos: Akal.

Charles-Dominique, L. (2011). "La patrimonialisation musicale française à l'épreuve du nomadisme des Roms". En Territoires musicaux mis en scène (pp. 147-162). Montréal: Les Presses de l'Université de Montréal.

Chang, L. (2011). "Le paradoxe du milieu touristique dominican”. En Territoires musicaux mis en scène (pp. 41 60). Montréal: Les Presses de l'Université de Montréal.

Cohen, J. (2011). "Portuguese Crypto-Jews and constructed musical identities". En Territoires musicaux mis en scène (pp. 325-337). Montréal: Les Presses de l'Université de Montréal.

Cole, R. (2018). Notes on troubling "the popular". Popular Music, 37/3, 392-414.

Dawe, K. (1998). "Bandleaders in Crete: musicians and entrepreneurs in a Greek island economy”. British Journal of Ethnomusicology, 7, 23-44.

Denning, M. (2015). Noise Uprising. The Audiopolitics of a World Musical Revolution. London \& New York: Verso.

Desroches, M. (2011). “Musique touristique et patrimoine à la Martinique”. En Territoires musicaux mis en scène (pp. 61-74). Montréal: Les Presses de l'Université de Montréal.

Eli, V. (2010). “Fiesta y Música en la santería cubana”. En A tres bandas. Mestizaje, sincretismo e hibridación en el espacio sonoro iberoamericano (pp. 173-180). Tres Cantos: Akal.

Erlmann, V. (1991). African Stars. Studies in Black South African Performance. Chicago \& London: The University of Chicago Press.

Escribano, J. (2018). "Anthony Seeger: How Does Ethnomusicology Matter? The socio-Political Relevance of Ethnomusicology in the 21st Century. Universidad de Valladolid, 16 de mayo de 2018". Cuadernos de etnoMusicologia 12. Recuperado de http://www.sibetrans.com/etno/cuaderno/30/cuadernos-de-etnomusicologia-n-12.

Finnegan, R (1989). The hidden musicians. Music-making in an English town. Cambridge: Cambridge University Press.

Giannattasio, F. (1992). Il concetto di musica: Contributi e prospettive della ricerca etnomusicologica. Roma: La Nuova Italia Scientifica.

Giannattasio, F. (2017).“Perspectives on a 21st Century Comparative Musicology: an Introduction”. En Perspectives on a 21st Century comparative Musicology: Ethnomusicology or Transcultural Musicology?, 10-29. Francesco Giannattasio y Giovanni Giuriati, eds. Udine: Nota.

Giuriati, G. (2017a). "Some reflections on a new Perspective in Transcultural Musicology: the area of Naples as a Case Study". En Perspectives on a 21st Century comparative Musicology: Ethnomusicology or Transcultural Musicology?, 136-145. Francesco Giannattasio \& Giovanni Giuriati, eds. Udine: Nota.

Giuriati, G. (2017b). "The Music for the Festa dei Gigli in Nola". En Perspectives on a 21st Century comparative Musicology: Ethnomusicology or Transcultural Musicology?, 146-156. Francesco Giannattasio \& Giovanni Giuriati, eds. Udine: Nota. 
González, J. P. (2001). Musicología popular en América Latina: Síntesis de sus logros, problemas y desafíos. Revista Musical Chilena, 55/195, 38-64.

González-Hernández, G. (2016). “Continuidad y adaptación de los tamborileros y piteros yokot’an de Nacajuca, Tabasco". En Los sonidos de nuestros pueblos. Escuchas desde el Sur (pp. 103-114). Tuxtla Gutiérrez: UNICACH.

Green, L. (2003). “Music Education, Cultural Capital, and Social Group Identity”. En The Cultural Study of Music. a critical introduction (pp. 263-273). New York \& London: Routledge.

Hamm, Ch. (1995). “Modernist Narratives and Popular Music." En Putting Popular Music in Its Place, 1-40. Cambridge: Cambridge University Press.

Hernández-López, G. (2016). “La música en los espacios festivos y ceremoniales de los jakaltekos del ejido Guadalupe Victoria, en Amatenango de la Frontera, Chiapas". En Los sonidos de nuestros pueblos. Escuchas desde el Sur (pp. 87-101). Tustla Gutiérrez: UNICACH.

Kunst, J. (1955). Ethnomusicology: A Study of its Nature, its Problems, Methods and Representative Personalities to Which Is Added a Bibliography. 2a ed. ampliada de Musicologica. The Hague: M. Nijhoff.

Madrid, A. (2010). “Música y nacionalismos en Latinoamérica”. En A tres bandas. Mestizaje, sincretismo e hibridación en el espacio sonoro iberoamericano (pp. 227-235). Tres Cantos: Akal.

Manabe, N. (2013). Music in Japanese Aantinuclear Demonstrations: The Evolution of a Contentious Performance Model. The Asia-Pacific Journal, 11/42/3. https://apjjf.org/2013/11/42/Noriko-Manabe/4015/ article.html

Manuel, P. (1988). Popular Musics of the Non-Western World: An Introductory Survey. New York: Oxford University Press.

Mark, A. (2011). “Divided Kingdom Republic's Zimbabwean hip-hop in London”. En Territoires musicaux mis en scène (pp. 399-414). Montréal: Les Presses de l'Université de Montréal.

McSherry, P. (2015).Chilean New Song. The Political Power of Music, 1960s-1973. Philadelphia: Temple University Press.

Menezes, R. J. (1999). "The origin of 'samba' as the invention of Brazil (why do songs have music?)". British Journal of Ethnomusicology, 8, 67-95.

Merriam, A. P. ([1977] 2001). “Definiciones de 'musicología comparada' y 'etnomusicología': una perspectiva histórico-teórica”. En Las culturas musicales. Lecturas de etnomusicología (pp. 59-78. Madrid: Trotta).

Middleton, R. (1990). Studying Popular Music. Milton Keynes: Open University Press.

Middleton, R. (2003). "Locating the People: Music and the Popular". En The Cultural Study of Music. a critical introduction (pp. 251-262). New York \& London: Routledge.

Moore, A. (ed.). (2003). Analysing Popular Music. Cambridge: Cambridge University Press.

Napier, J. (2011) “Kodava song as private resistance”. En Territoires musicaux mis en scène (pp. 209-226). Montréal: Les Presses de l'Université de Montréal.

Neal, M. A. (1999). What the Music Said. Black Popular Music and Black Popular Culture. New York \& London: Routledge.

Negus, K. ([1999] 2005). Los géneros musicales y la cultura de las multinacionales. Barcelona: Paidós.

Ochoa-Gautier, A. (2014). Aurality. Listening \& Knowledge in Nineteenth-Century Colombia. Durham and London: Duke University Press.

Reily, S.A. (1994). "Musical performance at a Brazilian festival”. British Journal of Ethnomusicology, 3 (1), 1-34.

Rhodes, W. (1957). On the subject of ethno-musicology". Ethno-Musicology Newsletter, 1.7, 4. 
Rice, T. (2014). Ethnomusicology in Times of Trouble. Yearbook for Traditional Music, 46, 191-209.

Romero, R. R. (1986). La investigación musical en América del Sur. Letras, 90, 71-92.

Rose, T. (1994). Black Noise. Rap Music and Black Culture in Contemporary America. Middletown: Wesleyan University Press.

Ruiz, I. (2018). La "conquista espiritual" no consumada. Cosmología y rituales mbyá-guaraní. Quito: Ediciones Abya-Yala.

Sardo, S. (2010). Guerras de Jasmin e Mogarim. Música, Identidade e Emoções em Goa. Alfragide: Texto.

Schneider, M. (1954). En defensa del Cancionero popular de la provincia de Madrid. Anuario Musical, IX, 254-257.

Simonett, H. (2001). Banda. Mexican Musical Life across Borders. Middletown: Wesleyan University Press.

Stokes M. (1992). The media and reform: The saz and elektrosaz in urban Turkish folk music. British Journal of Ethnomusicology, 1:1, 89-102.

Stokes M. (2003). "Globalization and the Politics of World Music". En The Cultural Study of Music. a critical introduction (pp. 297-308). New York \& London: Routledge.

Tagg, P. (1979). Kojak:50 Seconds of Television Music; Towards the Analysis of Affect in Popular Music. Skrifter från Musikvetenskapliga institutionen, Göteborg 2. Göteborg: Musikvetenskapliga Institutionen, Göteborgs univ.

Travassos, E. (2000). "Ethics in the sung duels of north-eastern Brazil: collective memory and contemporary practice". British Journal of Ethnomusicology, 9.1, 61-94.

Taylor, T. D. (2001). Strange Sounds. Music, Technology \& Culture. New York \& London: Routledge.

Turino, T. (1984). "The urban-mestizo charango tradition in southern Peru: a statement of shifting identity". Ethnomusicology, 28(2), 253-270.

Valenzuela, J. M. (2003). Jefe de jefes. Corridos y narcocultura en México. La Habana: Casa de las Américas.

Van der Merwe, P. (1989). Origins of the Popular style. The Antecedents of Twentieth-Century Popular Music. Oxford: Oxford University Press.

Vega, C. ([1966]1979). Mesomúsica: un ensayo sobre la música de todos. Revista del Instituto de Investigación Musicológica Carlos Vega, 3/3, 4-16.

Viveiros, M. L. (2004). Cultura popular e sensibilidade romântica: as danças dramáticas de Mário de Andrade. Revista Brasileira de Ciências Sociais, 19 / 54, 57-79.

Wade, P. (2000) Music, Race, and Nation. Música Tropical in Colombia. Chicago \& London: The University of Chicago Press.

Waisman, L. (2020) "Subalternidad en músicas novohispanas: dos fragmentos”. En De Nueva España a México. El universo musical mexicano entre centenarios (1617-1917) ed. Javier Marín-López (pp. 591-608). Sevilla: Universidad Internacional de Andalucía. 